\title{
The Point of Assertion is to Transmit Knowledge*
}

\author{
John Turri \\ john.turri@gmail.com
}

Abstract: Recent work in philosophy and cognitive science shows that knowledge is the norm of our social practice of assertion, in the sense that an assertion should express knowledge. But why should an assertion express knowledge? I hypothesize that an assertion should express knowledge because the point of assertion is to transmit knowledge. I present evidence supporting this hypothesis.

Keywords: assertion; knowledge; certainty; norms

Word count: 2124

Philosophers and cognitive scientists have recently argued that knowledge is the norm of our social practice of assertion (for reviews, see Benton 2014; Benton ms; Turri 2016). According to this hypothesis, an assertion should express knowledge. The hypothesis is supported by observational data connecting assertion to knowledge. We can prompt an assertion by asking whether someone has knowledge (e.g. "Do you know what time it is?") (Turri 2010a). When questioned, we can abstain from making an assertion by citing lack of knowledge (e.g. "Sorry, I don't know") (Reynolds 2002). And we can challenge an assertion by referencing knowledge (e.g. "Do you really know that?" or "You don't know what you're talking about") (Unger 1975). The hy-

\footnotetext{
* This is the penultimate version of a paper to appear in Analysis. Please cite the final, published version if possible.
} 
pothesis is also supported by experimental results. For example, in one study researchers told participants that an agent either believed a true proposition, was certain of that proposition, or knew that proposition. Participants who were told that the agent knew were significantly more likely to judge that the agent should make an assertion (Turri, Friedman \& Keefner in press; see also Turri in press a). Another study manipulated whether participants were told that an agent either knows or does not know a proposition. The manipulation dramatically affected whether people judged that the agent should assert the proposition: people strongly judged that the agent should make the assertion when she knew, but they strongly judged that she should not make the assertion when she did not know (Turri 2015a). Other studies have tested and ruled out the most common objections to the hypothesis, including situations involving reasonable false beliefs (Turri 2013), "selfless assertions" (Turri 2015b) and "Gettiered" assertions (Turri in press b; Turri in press c).

Overall, the evidence strongly supports the hypothesis that knowledge is the norm of assertion. But why is knowledge the norm of assertion? Why should an assertion express knowledge? In this paper, I provide initial evidence for an answer to this question. The answer is that an assertion should express knowledge because the point of the practice of assertion is to transmit knowledge. An assertion that does not express knowledge does not transmit knowledge, so an assertion should express knowledge. Arguably this is related to what one philosopher had in mind when he wrote that the "essential character" of assertion is "knowledgetransmission" (McDowell 1998, pp. 39-40).

Evidence supporting my answer comes from how we preface assertions and questions 
prompting assertions. We can and often do preface assertions with "just so you know" or other expressions implicating knowledge, such as "just so you're aware" or "just so you remember." It is perfectly natural to say, "Just so you know, our guests arrive at noon." But it is unnatural to preface assertions in ways reflective of alternative theories about the norm of assertion. According to alternative theories, the norm is belief (Bach \& Harnish 1979; Bach 2008), certainty (Stanley 2008), evidence (Hill \& Schechter 2007; Lackey 2007), or truth (Weiner 2005). For example, it would be odd to say, "Just so you believe this, our guests arrive at noon," "Just so you're certain, our guests arrive at noon," or "Just so you have (some) evidence, our guests arrive at noon." And it is absurd to say, "Just so it's true, our guests arrive at noon."

A related pattern emerges when we turn to prefacing questions used to prompt assertion. We can preface prompts with "just so I know" or other expressions that implicate knowledge, such as "just so I'm aware" or "just so I remember." It is natural to say, "Just so I know, do our guests arrive at noon?" But it is unnatural to preface a question with "just so I have a belief" ("just so I believe," "just so I have an opinion"), "just so it's true," or "just so I have (some) evidence." No one ever says these things. However, it does seem acceptable to preface prompts with "just so I'm certain." We do sometimes say things like, "Just so I'm certain, do our guests arrive at noon?"

If the point of assertion is knowledge transmission, then we can explain these interesting patterns in prefaces. The natural prefaces indicate that the point of the assertion or prompt is no more, and no less, than achieving the point of assertion. They specify the speech act's relevance by reference to knowledge-transmission specifically. In this respect, the natural prefaces seem 
interestingly similar to relevance conditionals, such as, "If [In case] someone gets hurt, there's a first-aid kit in the closet." In a relevance conditional, the antecedent does not specify a circumstance in which the consequent is true; instead, it specifies the circumstance in which the consequent is relevant (Austin 1946; Bhatt \& Pancheva 2006). For example, someone's injury does not make it true that a first-aid kit is in the closet; instead, it specifies a circumstance where it is relevant that a first-aid kit is in the closet.

Social and introspective observation is a good place to start when studying familiar social activities, such as assertion. But we should not draw firm conclusions from reported patterns in a single researcher's experience. On the one hand, the researcher's experience might be idiosyncratic. On the other hand, the researcher's theoretical commitments might cause him or her to selectively keep track of, or misinterpret, observations. One way to avoid these problems is to test a researcher's observational claims against the judgments of a large sample of competent, theoretically-uncommitted language users experienced in the social practice of assertion. In this spirit, I conducted a study to test my observational claims made above.

Participants ${ }^{1}$ were randomly assigned to one of two conditions, assert and prompt (betweensubjects). They read a brief scenario about a married couple, Sally and Jeff, responded to two questions, then completed a brief demographic survey after testing. The scenario was very simi-

${ }^{1} \mathrm{~N}=70$, aged $18-59$ years, mean age $=32$ years, 22 female, $96 \%$ reporting native competence in English. Participants were U.S. residents, recruited and tested online using Amazon Mechanical Turk and Qualtrics, and compensated $\$ 0.40$ for approximately 2 minutes of their time. Repeat participation was prevented. 
lar in both conditions. The main difference was that it focused on either Sally giving Jeff some information (assert), or Jeff requesting some information from Sally (prompt).

In the assert condition, Sally realizes that she forgot to tell Jeff that she invited guests over to watch the game. After reading the scenario, participants responded to two questions. First, they were asked, "In terms of how people ordinarily talk, what would be the most natural way for Sally to inform Jeff?” There were six options (rotated randomly):

1. Just so you know, we have company arriving at noon. (know)

2. Just so you're aware, we have company arriving at noon. (aware)

3. Just so you believe this, we have company arriving at noon. (believe)

4. Just so you have evidence, we have company arriving at noon. (evidence)

5. Just so you're certain, we have company arriving at noon. (certain)

6. Just so it's true, we have company arriving at noon. (true)

Participants then went to a new screen and were asked, "In terms of how people ordinarily talk, how natural or unnatural would it be for Sally to inform Jeff in the following ways?" The same six items then appeared in a matrix table below (order rotated randomly). Responses were collected using a standard 7-point Likert scale anchored with "very unnatural" (=1), "unnatural," "somewhat unnatural," "neither" (=4), "somewhat natural," "natural," and "very natural" (=7), left-to-right on the participant's screen.

In the prompt condition, Jeff realizes that Sally did not tell him what time people were due to arrive. After reading the scenario, participants responded to two questions. First, they were asked, "In terms of how people ordinarily talk, what would be the most natural way for Jeff to 
ask Sally?" There were six options (rotated randomly):

1. Just so I know, do our guests arrive at noon? (know)

2. Just so I'm aware, do our guests arrive at noon? (aware)

3. Just so I have a belief, do our guests arrive at noon? (believe)

4. Just so I have evidence, do our guests arrive at noon? (evidence)

5. Just so I'm certain, do our guests arrive at noon? (certain)

6. Just so it's true, do our guests arrive at noon? (true)

Participants then went to a new screen and were asked, "In terms of how people ordinarily talk, how natural or unnatural would it be for Jeff to ask in the following ways?" The same six items appeared in a matrix table below and were evaluated the same way as in the assert condition.

Figure 1 visualizes the results. In each condition, participants selected as most natural the knowledge preface. In each condition, participants rated the prefaces involving knowledge and awareness as natural, and they rated the prefaces involving belief, evidence, and truth as unnatural. Only for the certainty preface was there a noteworthy difference between naturalness ratings in the two conditions: participants rated the preface as unnatural in the assert condition, but they rated it as natural in the prompt condition. ${ }^{2}$

${ }^{2}$ Independent samples t-test comparing naturalness ratings for the certainty preface in the assert/ prompt conditions: $\mathrm{M}=2.83 / 5.26, \mathrm{SD}=1.36 / 1.29, \mathrm{t}(68)=-7.66, \mathrm{p}<.001$. The size of the mean difference was very large, $\mathrm{MD}=-2.43[-3.06,-1.80], \mathrm{d}=1.86$. 
(A) Most Natural

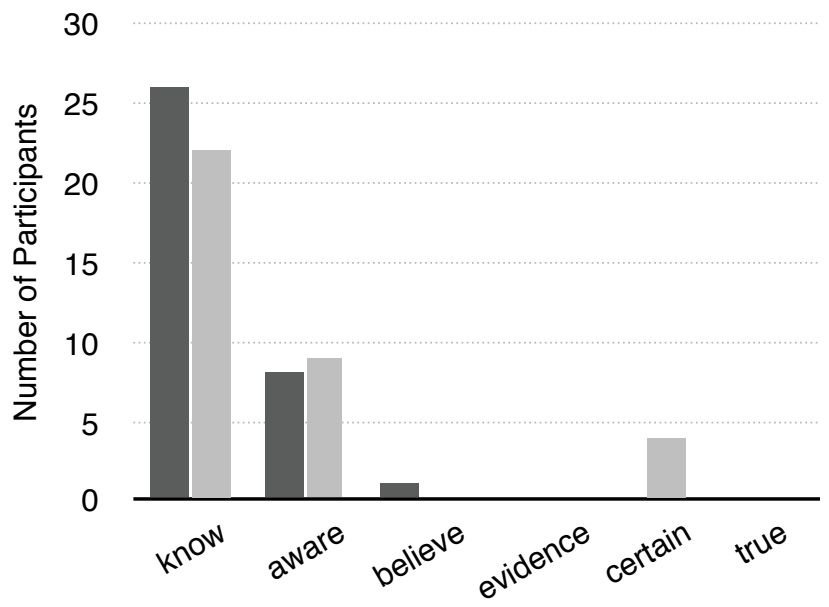

(B) How Natural

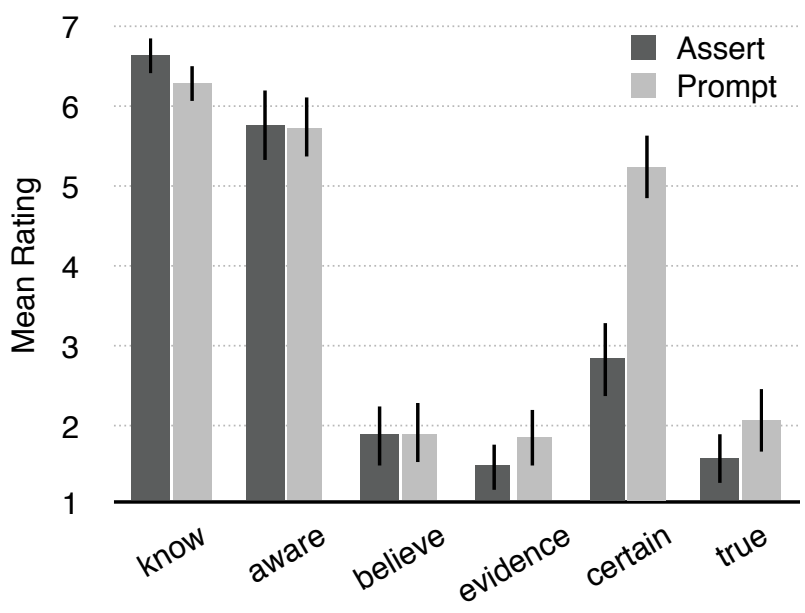

Fig. 1. Panel A: number of participants selecting the different prefaces as "most natural" for an assertion or prompt. Panel B: mean ratings of "how natural or unnatural" it is to preface an assertion or prompt in six different ways. Scales ran 1 (very unnatural) - 7 (very natural). Error bars represent bootstrapped $95 \%$ confidence intervals.

These results strongly support the observational claims made above. Prefaces involving knowledge or a state implicating knowledge (awareness) were viewed as the most natural. Prefaces involving belief, evidence, and truth were uniformly judged unnatural. Prefaces involving certainty were judged differently depending on whether they accompanied an assertion (unnatural) or a prompt (natural). Overall, this supports the hypothesis that the point of the social practice of assertion is to transmit knowledge. Or, put more simply, knowledge-transmission is the point of assertion.

The hypothesis that knowledge-transmission is the point of assertion sheds further light on an important recent discovery in philosophy and cognitive science - namely, that knowledge is the norm of our social practice of assertion. As mentioned above, a wealth of observational and experimental evidence supports this discovery. But it also raises an important question: why should an assertion express knowledge? The present results support a specific answer: because 
knowledge-transmission is the point of assertion. Assertions that do not express knowledge fail to promote the goal of the practice and, consequently, could incrementally undermine the practice (see also Turri in press d).

The results reported above motivate further investigation into the relationships among knowledge, certainty, and assertion. Previous observational and experimental evidence shows that although knowledge is clearly the most normatively relevant status for evaluating assertions, certainty might play an interesting normative role too. For instance, in addition to challenging an assertion by asking, "How do you know?", we can also ask, "How can you be certain?" (Stanley 2008). In response, researchers have noted that while we naturally prompt assertions by asking about what someone knows (e.g. "Do you know what time they arrive?"), it is unnatural to prompt assertions by asking about what someone is certain of (e.g. "Are you certain (about) what time they arrive?"); and, thus, they conclude that assertability is more closely linked to knowledge than to certainty (Turri 2010). Nevertheless, the present results suggest that the unnaturalness of certainty-prompts does not extend to referencing one's own certainty when prompting assertion: it is judged natural to ask, "Just so I'm certain, do our guests arrive at noon?"

One possibility is that the naturalness of the preface "just so I'm certain" derives not from a normative connection to assertion but, rather, questioning. A question is a prompt to assertion, and a good assertion answers the question. It would be satisfying if this reciprocity was reflected in the point of the social practices of questioning and asserting. One possibility is that the point of assertion is transmitting knowledge and the point of questioning is acquiring knowledge. Beyond the satisfaction felt at this symmetry, there is some evidence that knowledge-acquisition is 
the point of questioning. For instance, if someone asks a question, the response "You already know the answer to that" or "You know very well that I don't know the answer" suggest that it was pointless to ask the question. (Here I set aside pedagogical contexts where the point of questioning is to test for auditor knowledge.) Moreover, the present results support the hypothesis that knowledge-acquisition is a point of the practice of questioning, as indicated by the naturalness of the preface "just so I know." Nevertheless, the present results also suggest that another point could be reaching certainty, as indicated by the naturalness of the preface "just so I'm certain."

Philosophers have said and assumed many things about the relationship between knowledge and certainty (see especially Descartes 1641; Unger 1975; see also Wittgenstein 1975; Moore1959; Klein 1981; Chisholm 1989). But very little is known about how these categories are related in ordinary social cognition. Thus, while the present results support the hypothesis that knowledge-transmission is the point of assertion, they also suggest the need for further research into these issues.

Acknowledgments — For helpful comments and feedback, I thank Matthew Benton and Angelo Turri. This research was supported by the Social Sciences and Humanities Research Council of Canada and an Early Researcher Award from the Ontario Ministry of Economic Development and Innovation. 


\section{References}

Austin, J. L. (1946). Other minds. Proceedings of the Aristotelian Society, 20, 148-187.

Bach, K. (2008). Applying pragmatics to epistemology. Philosophical Issues, 18(1), 68-88.

Bach, K., \& Harnish, R. M. (1979). Linguistic communication and speech acts. Cambridge, Mass. : MIT Press.

Benton, M. A. (2014). Knowledge norms. Retrieved January 2014, from http://www.iep.utm.edu/ kn-norms/

Benton, M. A. (ms). Knowledge and Language. Notre Dame University.

Bhatt, R., \& Pancheva, R. (2006). Conditionals. In M. Everaert, H. V. Van Riemsdijk, R. Goedemans, \& B. Hollebrandse (Eds.), The Blackwell Companion to Syntax (Vol. 1, pp. 638686). Wiley-Blackwell.

Chisholm, R. (1989). Theory of Knowledge (3rd ed.). Englewood Cliffs, NJ: Prentice Hall.

Descartes, R. (2006). Meditations on first philosophy. In R. Ariew \& D. Cress (Ed. \& Trans.), Meditations, objections, and replies. Indianapolis: Hackett.

Hill, C., \& Schechter, J. (2007). Hawthorne's lottery puzzle and the nature of belief. Philosophical Issues, 17, 102-122.

Klein, P. (1981). Certainty: a refutation of scepticism. Minneapolis: University of Minnesota Press.

Lackey, J. (2007). Norms of assertion. Nous, 41(4), 594-626.

McDowell, J. H. (1998). Meaning, knowledge, and reality. Cambridge, Mass.: Harvard Universi- 
ty Press.

Moore, G. E. (1959). Philosophical papers. New York: Collier Books.

Reynolds, S. L. (2002). Testimony, knowledge, and epistemic goals. Philosophical Studies, 110(2), 139-161.

Stanley, J. (2008). Knowledge and certainty. Philosophical Issues, 18, 35-58.

Turri, J. (2010). Prompting challenges. Analysis, 70(3), 456-462. http://doi.org/10.1093/analys/ anq027

Turri, J. (2013). The test of truth: An experimental investigation of the norm of assertion. Cognition, 129(2), 279-291. http://doi.org/10.1016/j.cognition.2013.06.012

Turri, J. (2015a). Knowledge and the norm of assertion: a simple test. Synthese, 192(2), 385392. http://doi.org/10.1007/s11229-014-0573-4

Turri, J. (2015b). Selfless assertions: some empirical evidence. Synthese, 192(4), 1221-1223. http://doi.org/10.1007/s11229-014-0621-0

Turri, J. (2016). Knowledge and the norm of assertion: an essay in philosophical science. Open Book Publishers.

Turri, J. (in press a). Knowledge, certainty and assertion. Philosophical Psychology.

Turri, J. (in press b). Knowledge and assertion in Gettier cases. Philosophical Psychology

Turri, J. (in press c). Vision, knowledge, and assertion. Consciousness \& Cognition

Turri, J. (in press d). Sustaining rules: a model and application. In J. A. Carter, E. C. Gordon, \& B. Jarvis (Eds.), Knowledge first. Oxford University Press.

Turri, J., Friedman, O., \& Keefner, A. (in press). Knowledge central: a central role for knowledge 
attributions in social evaluations. Quarterly Journal of Experimental Psychology.

Unger, P. (1975). Ignorance: a case for skepticism. Oxford: Oxford University Press.

Weiner, M. (2005). Must we know what we say? Philosophical Review, 114(2), 227-251.

Wittgenstein, L. (1975). On certainty. (G. Anscombe \& G. H. V. Wright, Eds., D. Paul \& G. Anscombe, Trans.). Malden, MA: Blackwell. 